\title{
Effect of gender, facial dimensions, body mass index and type of functional occlusion on bite force
}

\author{
Duygu KOÇ ${ }^{1}$, Arife DOĞAN² ${ }^{2}$ Bülent BEK²
}

1- DDS, Department of Prosthodontics, Faculty of Dentistry, Gazi University, Ankara, Turkey.

2- DDS, PhD, Department of Prosthodontics, Faculty of Dentistry, Gazi University, Ankara, Turkey.

Corresponding address: Duygu Koç - Department of Prosthodontics - Faculty of Dentistry - Gazi University - Ankara - Turkey - 06510 - Phone:+9 03122034196 Fax:+9 03122239226 e-mail: dtduygukc@hotmail.com - duygukoc@gazi.edu.tr

Received: July 19, 2009 - Modification: March 24, 2010 - Accepted: May 25, 2010

\section{ABSTRACT}

\begin{abstract}
bjective: Some factors such as gender, age, craniofacial morphology, body structure, occlusal contact patterns may affect the maximum bite force. Thus, the purposes of this study were to determine the mean maximum bite force in individuals with normal occlusion, and to examine the effect of gender, facial dimensions, body mass index (BMI), type of functional occlusion (canine guidance and group function occlusion) and balancing side interferences on it. Material and Methods: Thirty-four individuals aged 19-20 years-old were selected for this study. Maximum bite force was measured with strain-gauge transducers at first molar region. Facial dimensions were defined by standardized frontal photographs as follows: anterior total facial height (ATFH), bizygomathic facial width (BFW) and intergonial width (IGW). BMI was calculated using the equation weight/height ${ }^{2}$. The type of functional occlusion and the balancing side interferences of the subjects were identified by clinical examination. Results: Bite force was found to be significantly higher in men than women $(p<0.05)$. While there was a negative correlation between the bite force and ATFH/BFW, ATFH/IGW ratios in men $(p<0.05)$, women did not show any statistically significant correlation $(p>0.05)$. BMI and bite force correlation was not statistically significant $(p>0.05)$. The average bite force did not differ in subjects with canine guidance or group function occlusion and in the presence of balancing side interferences $(p>0.05)$. Conclusions: Data suggest that bite force is affected by gender. However, BMI, type of functional occlusion and the presence of balancing side interferences did not exert a meaningful influence on bite force. In addition, transverse facial dimensions showed correlation with bite force in only men.
\end{abstract}

Key words: Bite force. Gender. Facial dimensions. Body mass index. Occlusal guidance.

\section{INTRODUCTION}

Maximum bite force is an indicator of the functional state of the masticatory system ${ }^{29}$. It has been widely used in dentistry mainly to understand the mechanics of mastication for evaluation of the therapeutic effects of prosthetic devices and to provide reference values for the studies on the biomechanics of prosthetic devices ${ }^{8}$. There are several studies confirming a direct relationship between masticatory performance and maximum bite force ${ }^{23}$.

A wide range of maximum bite force values reported in different studies have been attributed to some factors related to the anatomical and physiological characteristics of the subjects as well as the recording techniques employed. Bite force can be measured with various devices such as strain-gage transducers, piezoelectric film, gnathodynamometer, quartz force transducer, pressure-sensitive sheet or force-sensing resistors ${ }^{11}$.

In the literature, a number of studies have investigated the effects of various factors such as craniofacial morphology ${ }^{1,26,27}$, gender ${ }^{9,28}$, body height and weight ${ }^{4,13}$ and occlusal contact pattern ${ }^{1}$ on bite force. The relationship between craniofacial morphology and bite force has been generally studied by cephalometrics ${ }^{1,10,24,26,27}$. 
Although cephalometrics is the standard for characterizing skeletal and dental craniofacial morphology in clinical practice, the patients who have cephalograms taken absorb a small amount of radiation which may be hazardous especially for specific cases $^{30}$. Alternatively, facial photographs have been proposed as a well-established clinical and research tool for the assessment of craniofacial morphology and deformities; it provides points and landmarks for complete analytical measurements evaluation without patient exposure to potentially harmful radiation ${ }^{6,27}$. Zhang, et al. ${ }^{30}$ (2007) compared standardized cephalometrics and photographic measurements and concluded that both linear and angular measurements were useful and reliable methods for characterizing facial morphology. However, a few studies have investigated the correlation between bite force and face morphology with facial photographic analysis ${ }^{3,6,27}$.

Gender difference have drawn the most attention as a factor affecting the bite force and it is generally accepted that bite force is higher in men than in women $3,5,9,28$, which is likely due to muscular or tooth size differences between them ${ }^{9,28}$. However, in a recent study no gender difference has been reported ${ }^{1}$. As another influencing factor, body mass index (BMI) has also been taken into consideration. Linderholm and Wennström ${ }^{13}$ (1969) stated that bite force positively correlated with body height and weight, whereas Braun, et al. ${ }^{4}$ (1995) found low correlation between them.

Determining the effect of the occlusal contact pattern on bite force may be used to provide valuable information for prosthetic treatment and help to avoid excessive bite force in subjects who have parafunctional activities and temporomandibular disorders. In the literature, group function and canine guidance occlusion have both been described as being clinically acceptable elements of a functional occlusion ${ }^{20}$. However, there have been very few lines of scientific evidence indicating that canine guidance occlusion is better or worse than group function occlusion ${ }^{20}$. Further, the effect of balancing side interferences is disputed ${ }^{21}$. Okeson ${ }^{22}$ (1989) stated that balancing side interferences are perceived by the neuromuscular system differently from other occlusal contacts and can be destructive to the masticatory system and neuromuscular responses. On the other hand, it has been stated that balancing side interferences reduced the amplitude of mandibular displacements ${ }^{20}$, and had a protective role for ipsilateral temporomandibular joint ${ }^{17}$. Therefore, there is no evidence concerning whether these contacts were beneficial or not for the function of the masticatory system ${ }^{16}$.

The the purposes of this study were to determine the mean maximum bite force in individuals with normal occlusion, and to examine the effect of gender, facial dimensions, BMI, type of functional occlusion (canine guidance and group function occlusion) and balancing side interferences on it.

\section{MATERIAL AND METHODS}

\section{Sample selection}

Seventeen male and 17 female Turkish dental students volunteered to participate in this study. This research was approved by the Research Ethics Committee of Gazi University (Process\# 20/2009). All participants received written explanation of the research purposes and were informed before the start of the study. The age range of the students was 19-20 years-old. All participants had no reported systemic disease or apparent facial asymmetry, no craniofacial trauma or surgery, no temporomandibular joint dysfunction, no periodontal disease, and no orthodontic treatment. They all had Angle Class 1 molar relationship on both sides without an anterior or posterior crossbite or open bite, full permanent dentition (not including third molars), and vital first molars without mesiooccluso-distal restorations.

\section{Bite force recordings}

Maximum bite forces were measured from each side of the dental arch using two miniature straingage transducers (Model VLPB; Load Cell Central, Monroeton, PA, USA) with stainless steel cases. Two transducers were placed bilaterally on a flat metal arch. The metal surfaces of the arch were covered with plaster (Betasan, Kocaeli, Turkey). The metal arch and transducers were further covered by a disposable latex finger cot to avoid contamination during measurements. Each transducer has a height of $4 \mathrm{~mm}$ and a diameter of $12 \mathrm{~mm}$; with these applications transducers reached a height of $6 \mathrm{~mm}$.

Bite force was detected as a two-channel signal from each side with a bio-signal acquisition device designed by Kardiosis (Tepa Inc.; Kardiosis Ltd. Co., Ankara, Turkey). The force signals were monitored online and then measured on a PC screen as $\mathrm{kg}$, using a specific software program developed by the same company. Calibration of the transducers was performed by loading the transducer with known force values, the deviation from linearity with a load of $5 \mathrm{~kg}$ was $+\% 2.66$ in right transducer and $+\% 4$ in left transducer, $15 \mathrm{~kg}$ was $+\% 5.2$ in right transducer and $+\% 2.6$ in left transducer.

During the test, subjects were seated in an upright position with the head in a natural posture, keeping the Frankfort plane approximately parallel to the floor. Initially, bilateral transducers that positioned on the metal plate were placed between the first molar teeth on both sides. The transducers were also maintained parallel to the Frankfort plane 
during recording. Subjects were instructed to bite as forcefully as possible three times. Before the recordings, the subjects were trained to perform their highest possible bite force. The highest value of each clenching was recorded and the mean value of the three highest clenching measurements was considered to be the subject's maximum bite force. The sum of the right and left bite force values was considered to be the maximum bite force.

\section{Facial dimensions and BMI}

Facial dimensions were determined by measurements of standardized frontal photographs. The camera (Cybershot DSC W110; Sony, Japan) was positioned at $140 \mathrm{~cm}$ distance from subjects on a tripod and adjusted to the same level of the subject's eyes. Photographs were taken in maximum intercuspation with the Frankfort plane approximately parallel to the floor. The obtained digital images were $2048 \times 1536$ pixels in size and 5,1 megapixels in resolution. The images were analyzed using Adobe Photoshop 7 (Adobe Inc., San Jose, CA, USA). The facial midline and interpupilary line were checked against a vertical and horizontal guideline to correct for any deviation of the face. The nasion, menton, zygion and gonion facial landmarks were identified on a digitized image to obtain the following linear measurements; ATFH (anterior total facial height; distance between nasion and menton), BFW (bizygomathic facial width; distance between right zygion and left zygion) and IGW (intergonial width; distance between right gonion and left gonion). These linear distances were measured using Adobe Photoshop 7. Then, following facial indices were calculated: ATFH/BFW and ATFH/IGW.

For each subject age, gender and body mass index derived from body height in meters and weight in kilograms were recorded. BMI was calculated using the equation weight $/$ height $^{2}(\mathrm{~kg} /$ $\left.\mathrm{m}^{2}\right)$.

\section{Examination of occlusal contact pattern}

The type of functional occlusion and balancing side interferences were determined by clinical examination. The interocclusal contacts were recorded with occlusal registration strips (65 $\mu \mathrm{m}$ thick) (Swedent; Swedish Dental Supplies AB, Akarp, Sweden). The types of functional occlusion were grouped classically into 2 major categories: Canine guidance and group function. The functional occlusion of all subjects were determined according to the following criteria; when the mandible was moved in edge to edge positions of canines approximately $3 \mathrm{~mm}$ right and left lateral position, if only the maxillary and mandibular canines came into contact on the working side while the posterior teeth are disoccluding, the subjects were said to have canine guidance. The subjects considered to have group function were those for whom the maxillary canine, premolars, and the mesiobuccal cusp of the first molar came into contact with the mandibular opposite teeth on the working side in 3 $\mathrm{mm}$ lateral position. The subjects who had balancing side interferences at the $1 \mathrm{~mm}$ lateral position were considered to have balancing side interferences when at least a pair of teeth came into contact on the non-working side.

Two investigators, who had been calibrated previously, performed all recordings in the same day. The experimental protocol including clinical examination and taking photographs of the subjects was performed by the same investigator. After completion of the clinical examination and taking photographs, all bite force recordings were carried out by another examiner who was not aware of the other findings.

\section{Statistical analysis}

All data were analyzed using the Statistical Package for Social Science (SPSS 9.0; SPSS Software Inc., Chicago, IL, USA). The Mann-Whitney $U$ test was used to determine gender differences in the bite force. The correlation between all facial dimensions and bite force was analyzed using the Pearson correlation analysis. The effect of the types of functional occlusion and presence of balancing side interferences on bite force were evaluated using the independent $t$-test. A value of $p<0.05$ was considered to be statistically significant.

\section{RESULTS}

The BMI, ATFH, ATFH/BFW and ATFH/IGW correlations with bite force are shown in Table 1. The relation between BMI and bite force was not statistically significant for either men or women $(p>0.05)$. Similarly, ATFH did not correlate with bite force in any group. While there were negative correlations between bite force and ATFH/BFW

Table 1- Pearson's correlation analysis of body mass index (BMI). Anterior total facial height (ATFH). Anterior total facial height/bizygomatic facial width (ATFH/BFW). Anterior total facial height/intergonial width (ATFH/IGW) with maximum bite force $(\mathrm{kg})$ in women and men

\begin{tabular}{lcccc}
\hline & \multicolumn{2}{c}{ Women } & \multicolumn{2}{c}{ Men } \\
& $\mathbf{R}$ & $\mathbf{p}$ & $\mathbf{R}$ & $\mathbf{p}$ \\
\hline BMI & -0.218 & 0.4 & 0.05 & 0.849 \\
ATFH & 0.013 & 0.959 & -0.224 & 0.386 \\
ATFH/BFW & 0.124 & 0.635 & -0.513 & 0.035 \\
ATFH/IGW & 0.223 & 0.389 & -0.502 & 0.04 \\
\hline
\end{tabular}

${ }^{*} \mathrm{R}=$ Pearson's correlation coefficient; $p=$ Probability values. 
Table 2- Means \pm standart deviations (SD) of maximum bite force and $p$ values in subjects according to type of functional occlusion, presence of balancing side interferences and gender ( ${ }^{*}$ means $\left.p<0.05\right)$

\begin{tabular}{lccccc}
\hline Variables & & N & Mean \pm SD & p \\
\hline Type of Functional & Occlusion & Group Functional & Men & 11 & $38 \pm 13.6$ \\
& & Women & 8 & $29.3 \pm 14.3$ & 0.269 \\
& Canine Guidance & Men & 6 & $31.1 \pm 6.8$ & 0.71 \\
\hline Presence of Balancing Side Interferences & Yes & Women & 9 & $27.2 \pm 6.57$ & $39.6 \pm 12.4$ \\
& & Men & 10 & $32.5 \pm 14.2$ & 0.095 \\
\hline Gender & No & Women & 7 & $29.8 \pm 9.15$ & 0.172 \\
\hline
\end{tabular}

or ATFH/IGW ratios in men, women did not show statistically significant correlations. The bite force of subjects according to type of functional occlusion, presence of balancing side interferences and gender is given in Table 2. The Mann Whitney $U$ test revealed that bite force was significantly higher in men than women $(p<0.05)$. The men and women with group function and canine guidance occlusion showed no statistically any significant difference $(p>0.05)$. In addition, the relationship between bite force and the presence of balancing side interferences showed no statistically significant difference in men and women ( $p>0.05)$.

\section{DISCUSSION}

Bite force is most often recorded using one or two transducers placed between a pair of opposing teeth during clenching. This is a simple direct method for clinical use; however it increases the bite height and leaves the rest of the dentition separated. Although an increased vertical dimension is also known to influence maximum bite force ${ }^{12}$, it has an effect in the same way in all subjects, and therefore, it should not influence the correlation between bite force and facial morphology.

The results indicated that men had statistically greater bite force values than women $(p<0.05)$. This finding is in accordance with other studies ${ }^{3,9,28}$ reporting that men have stronger bite force. However, it is in contrast to that of a study conducted by Abu Alhaija, et al. ${ }^{1}$ (2010), which found no significant difference between men and women regading maximum bite force. The effect of gender difference on bite force has been due mostly to the greater muscular potential of men ${ }^{28}$ which may be a result of anatomical differences ${ }^{25}$. The masseter muscles of men have type 2 fibers with larger diameters and greater sectional areas than those of women; and also hormonal differences might contribute to the composition of the muscle fibers $^{25}$. The lower bite force in women might also be due to a significantly lower pressure pain threshold during maximum biting and pressure pain intolerance in women as reported in another study ${ }^{14}$.

Based on the results related to facial dimensions, it was found that ATFH showed no correlation with bite force, while ATFH/BFW and ATFH/IGW had negative correlation with bite force only in men. It was seen that men with higher bite force had wider head dimensions in proportion to their ATFH; and longer faces presented lower bite force only in men. Similarly Bonakdarchian, et al. ${ }^{3}$ (2009) evaluated face forms based on digital photographs and measured its influence upon maximum molar bite force using strain-gage transducers. They stated that subjects with square face forms had higher bite force. In another study conducted by Raadsheer, et al. ${ }^{27}$ (1999), it has been reported that there was a positive relationship between transverse facial dimensions and bite force in adults. In these studies, it has been proposed that the mechanical advantage of masticatory muscles could be a contributing factor in higher bite force in subjects who had wider head dimensions. However, both of these studies were performed without gender difference. In the present study, no correlation between bite force and facial dimensions was recorded in women. The lack of correlation in female can be explained by the randomly selected subject samples, with no concentration of specific facial morphology or by the small number of subjects.

BMI is a composite of weight and height that represents a summary measure of the distribution of corporal mass ${ }^{7}$. Therefore, its relationship with bite force was also evaluated. The men who participated in the current study had higher BMI values compared to the women. However, no correlation between BMI and bite force was found. This is because the subjects who participated in the study were healthy young adults and did not have extreme BMIs. 
In several studies, the effect of the occlusal contact pattern on the masticatory system has been evaluated by the EMG activity of muscles ${ }^{2,15,21}$. In most of the studies, canine guidance showed less EMG activity than group function ${ }^{15,20}$, this occlusal contact pattern suggested to providing a decrease in muscle tension with occlusal splints ${ }^{15}$. However, there have been very few lines of scientific evidence indicating that canine guidance occlusion is better or worse than group function ${ }^{20}$. In the current study the effect of the occlusal contact pattern on the masticatory system was evaluated directly using bite force measurements between a pair of opposing teeth. The maximum bite force was found to be insignificantly higher in subjects with group function occlusion than in those with canine guidance. Similarly, Abu Alhaija, et al. ${ }^{1}$ (2010) compared the maximum bite force between occlusal contact patterns using a hydraulic pressure gauge and stated that bite force was not statistically significant in subjects with canine guidance and group function occlusion. The lack of correlation in both mentioned studies can be explained by the centric position of the mandible during bite force recordings. The effect of the functional occlusion type on bite force would be greater in lateral excursions as that type of functional occlusion shows its effect mainly during lateral excursions.

Occlusal contact patterns vary according to the mandibular position examined. There is no description regarding the mandibular position when examining occlusal contact, so the patterns of canine guidance and group function occlusion with the presence of balancing side interferences have been categorized differently in different studies ${ }^{18}$. Furthermore, it has been stated that balancing side contacts were significantly greater in the $1 \mathrm{~mm}$ positions than in the $3 \mathrm{~mm}$ positions ${ }^{19}$ therefore, in the current study balancing side interferences were recorded at a $1 \mathrm{~mm}$ lateral position. In the present study, men and women who had balancing side interferences demonstrated greater bite force values than those without such contacts, though without statistical significance $(p>0.05)$. To obtain more sound data in this respect, the effect of this parameter on the amount of forces during lateral excursions also needs to be determined in further studies.

\section{CONCLUSIONS}

Considering the sample size and the methodology used in this study, the following conclusions can be drawn: men had higher bite force value than women; BMI had no direct effect on bite force; transverse facial dimensions affected bite force only in men, indicating that men with long faces have a lower bite force than men with normal face; the type of functional occlusion and balancing side interferences had no influence on maximum bite force. A limitation of this study was its relatively small sample. Therefore the observed relationships require further studies investigating larger samples. However, this study provides a baseline data for further research.

\section{REFERENCES}

1- Abu Alhaija ES, Al Zo'ubi IA, Al Rousan ME, Hammad MM. Maximum occlusal bite forces in Jordanian individuals with different dentofacial vertical skeletal patterns. Eur J Orthod. 2010;32:71-7. 2- Akören AC, Karaağaçlıoğlu L. Comparison of the electromyographic activity of individuals with canine guidance and group function occlusion. J Oral Rehabil. 1995;22:73-7.

3- Bonakdarchian M, Askari N, Askari M. Effect of face form on maximal molar bite force with natural dentition. Arch Oral Biol. 2009;54:201-4.

4- Braun S, Bantleon HP, Hnat WP, Freudenthaler JW, Marcotte MR, Johnson BE. A study of bite force, part 1: relationship to various physical characteristics. Angle Orthod. 1995;65:367-72.

5- Calderon PS, Kogawa EM, Lauris JRP, Conti PCR. The influence of gender and bruxism on the human maximum bite force. J Appl Oral Sci. 2006;14:448-53.

6- Castelo PM, Bonjardim LR, Pereira LJ, Gavião MBD. Facial dimensions, bite force and masticatory muscle thickness in preschool children with functional posterior crossbite. Braz Oral Res. 2008;22:48-54.

7- Cosme DC, Baldisserotto SM, Canabarro SA, Shinkai RS. Bruxism and voluntary maximal bite force in young dentate adults. Int J Prosthodont. 2005;18:328-32.

8- Fernandes CP, Glantz PO, Svensson SA, Bergmark A. A novel sensor for bite force determinations. Dent Mater. 2003;19:118-26. 9- Ferrario VF, Sforza C, Serrao G, Dellavia C, Tartaglia GM. Single tooth bite forces in healthy young adults. J Oral Rehabil. 2004;31:18-22.

10- Ingervall B, Minder C. Correlation between maximum bite force and facial morphology in children. Angle Orthod. 1997;67:415-24. 11- Koc D, Dogan A, Bek B. Bite force and influential factors on bite force measurements: a literature review. Eur J Dent. 2010;4:223-32.

12- Lindauer SJ, Gay T, Rendell J. Effect of jaw opening on masticatory muscle EMG-force characteristics. ] Dent Res. 1993;72:51-5.

13- Linderholm $\mathrm{H}$, Wennström $\mathrm{A}$. Isometric bite force and its relation to general muscle forge and body build. Acta Odontol Scand. 1969;28:679-89.

14- Jensen R, Rasmussen BK, Pedersen B, Lous I, Olesen J. Cephalic muscle tenderness and pressure pain threshold in a general population. Pain. 1992;48:197-203.

15- Manns A, Chan C, Miralles R. Influence of group function and canine guidance on electromyographic activity of elevator muscles. J Proshet Dent. 1987;57:494-501.

16- Marklund S, Wänman A. A century of controversy regarding the benefit or detriment of occlusal contacts on the mediotrusive side. J Oral Rehabil. 2000;27:553-62.

17- Minagi S, Watanabe H, Sato T, Tsuru H. Relationship between balancing-side occlusal contact patterns and temporomandibular joint sounds in humans: proposition of the concept of balancingside protection. J Craniomand Disord. 1990;4;251-6.

18- Ogawa T, Ogimoto T, Koyano K. Pattern of occlusal contacts in lateral positions: canine protection and group function validity in classifying guidance patterns. J Prosthet Dent. 1998;80:67-74. 19- Ogawa T, Ogimoto T, Koyano $\mathrm{K}$. The relationship between non-working-side occlusal contacts and mandibular position. J Oral Rehabil. 2001;28:976-81. 
20- Okano N, Baba K, Akishige S, Ohyama T. The influence of altered occlusal guidance on condylar displacement. J Oral Rehabil. 2002;29:1091-8.

21- Okano N, Baba K, Igarashi Y. Influence of altered occlusa guidance on masticatory muscle activity during clenching. J Oral Rehabil. 2007;34:679-84.

22- Okeson JP. Management of temporomandibular disorders and occlusion. $2^{\text {nd }}$ ed. St Louis: Mosby; 1989. p.117-9.

23- Okiyama S, Ikebe K, Nokubi T. Association between masticatory performance and maximal occlusal force in young men. J Oral Rehabil. 2003;30:278-82.

24- Pereira LJ, Gavião MBD, Bonjardim LR, Castelo PM, Van Der Bilt A. Muscle thickness, bite force, and craniofacial dimensions in adolescents with signs and symptoms of temporomandibular dysfunction. Eur J Orthod. 2007;29:72-8.

25- Pizolato RA, Gavião MB, Berretin-Felix G, Sampaio AC, Trindade Junior AS. Maximal bite force in young adults with temporomandibular disorders and bruxism. Braz Oral Res. 2007; $21: 278-83$.
26- Proffit WR, Fields HW, Nixon WL. Occlusal forces in normal and long face adults. J Dent Res. 1983;62:566-71.

27- Raadsheer MC, Van Eijden TMGJ, van Ginkel FC, Prahl-Andersen

B. Contribution of jaw muscle size and craniofacial morphology to human bite force magnitude. J Dent Res. 1999;78:31-42.

28- Regalo SCH, Santos CM, Vitti M, Regalo CA, Vasconcelos PB, Mestriner J, et al. Evaluation of molar and incisor bite force in indigenous compared with white population in Brazil. Arch Oral Biol. 2008;53:282-6.

29- Van Der Bilt A, Tekamp FA, Van Der Glas HW, Abbink JH. Bite force and electromyograpy during maximum unilateral and bilateral clenching. Eur J Oral Sci. 2008;116:217-22.

30- Zhang X, Hans MG, Graham G, Kirchner HL, Redline S. Correlations between cephalometric and facial photographic measurements of craniofacial form. Am J Orthod Dentofacial Orthop. 2007;131:67-71. 